\title{
Pure Peroneal Intraneural Ganglion Cyst Ascending Along the Sciatic Nerve
}

\section{Siyatik Sinir Boyunca Illerleyen Saf Peroneal Intranöral Ganglion Kisti}

\author{
Ozkan TEHLI ${ }^{1}$, Ramazan Cengiz CELIKMEZ ${ }^{1}$, Baris BIRGILI ${ }^{1}$, Ilker SOLMAZ ${ }^{2}$, Ertugrul CELIK ${ }^{3}$ \\ ${ }^{1}$ Erzurum Maresal Cakmak Military Hospital, Department of Neurosurgery, Erzurum, Turkey \\ ${ }^{2}$ Gulhane Military Medical Academy, Department of Neurosurgery, Ankara, Turkey \\ ${ }^{3}$ Gulhane Military Medical Academy, Department of Pathology, Ankara, Turkey
}

Correspondence address: Ozkan TEHLI / E-mail: ozkantehli@gmail.com

\begin{abstract}
Peroneal nerve entrapment is most commonly seen in the popliteal fossa. It is rarely caused by a ganglion. Intraneural ganglia, although uncommon and seldom cause serious complications, are well recognized and most commonly affect the common peroneal (lateral popliteal) nerve. Ganglionic cysts developing in the sheath of a peripheral nerve or joint capsule may cause compression neuropathy. The differential diagnosis should involve L5 root lesions, posttraumatic intraneural hemorrhage, nerve compression near the tendinous arch located at the fibular insertion of the peroneal longus muscle and nerve-sheath tumors. We present a unique case of a pure intraneural ganglion of the common peroneal nerve ascending along the sciatic nerve. This case underscores the importance of consideration of an intraneural ganglion cyst with sciatic nerve involvement.
\end{abstract}

KEYWORDS: Ganglion cyst, Sciatic nerve, Peroneal nerve paralysis

öz

Peroneal sinir tuzaklanması en yaygın popliteal fossada görülür. Tuzaklanma nadir olarak ganglion kistinden kaynaklanır. Intranöral ganglion kisti az karşılaşılması ve nadiren ciddi komplikasyonlara neden olmasına rağmen iyi tanımlanmış olup çoğunlukla common peroneal siniri etkilemektedir. Peroneal sinirin kılıfından veya eklem kapsülünden gelişen ganglion kisti kompresyon nöropatisine neden olabilir. Ayırıcı tanı L5 kök lezyonları, posttravmatik intranöral hemoraji, peronealis longus adelesinin fibular insersiyon bölgesindeki tendinöz ark komşuluğundaki sinir sıkışması ve sinir kılıfı tümörlerini içermelidir. Common peroneal sinirin siyatik sinire uzanan saf intranöral ganglion kistinin nadir görülen bir örneğini sunuyoruz. Bu sunum, siyatik sinir tutulumu olan intranöral ganglion kistinin değerlendirilmesinin önemini vurgulamaktadır.

ANAHTAR SÖZCÜKLER: Ganglion kisti, Siyatik sinir, Peroneal sinir felci

\section{INTRODUCTION}

The incidence of intraneural ganglion is relatively rare, but frequently affects the common peroneal nerve. The origin of the intraneural ganglion is controversial. While some authors propose that it is an extension of the ganglion from the proximal tibiofibular joint (22), others suggest that the ganglion originates in the nerve itself $(1,15)$.

Leg pain, sensory loss, and weakness in ankle dorsiflexion comprise a symptom complex that is most frequently caused by degenerative disc disease of the lumbar spine. However, isolated peroneal nerve compression can mimic the abovementioned symptomatology of lumbar disc disease. However, little is known about the patho-mechanism of the nerve palsy caused by an intraneural ganglion and the major problem is misdiagnosis. Misdiagnosis of intraneural and extraneural ganglia, including failure to identify the joint origin, is a common problem. Preoperative distinction of these entities is possible and crucial for optimum patient management.
Intraneural ganglia are uncommon and many radiologists and surgeons may encounter these lesions very rarely, if at all, during their practice. As a result, the small joint connection may be unrecognized and untreated, resulting in a very high rate of recurrence (27).

We present a unique case of compression neuropathy of the common peroneal nerve with sciatic nerve involvement caused by an intraneural ganglion which was misdiagnosed as lumbar discopathy previously. We emphasize the importance of the evaluation of this rare case with magnetic resonance imaging (MRI), electromyography (emg), and ultrasonography as well as the treatment modalities.

\section{CASE REPORT}

A 22-year-old man presented with numbness and motor weakness in the lateral aspect of his right leg, present for 3 year, after the onset of severe pain. His medical history revealed a single episode of numbness, motor weakness and pain in his right leg which had caused hospitalization and 
resulted in the misdiagnosis of lumbar disc herniation. At that time, the patient was offered microdiscectom but was not willing to undergo surgery. The patient was unable to extend his right ankle and had a partial motor weakness of toe extension when he was referred to our hospital. Manual muscle testing of the right tibialis anterior, extensor hallucis longus, extensor digitorum longus, and peroneus muscles revealed muscle strength at the level of 2 (trace), 2 (trace), 3 (fair), and 3 (fair) respectively, according to the Daniels and Worthingham muscle power grading system (five grades: $0=$ zero to $5=$ normal) (12) Diminished sensation in the first web space, an area of tenderness over the region of the fibular head, and a positive Tinel's sign near the head of the fibula on the right foot were also detected during the examination. No mass lesion was palpable.

EMG revealed a severe right common peroneal neuropathy below the branch leading to the short head of the biceps femoris muscle, which predominantly affected the common peroneal nerve. No abnormality was found in the muscles innervated by the tibial nerve. However, further investigations were needed to identify the pathology. Ultrasonography was performed in order to compare the left and right peroneal nerves. A diffuse enlarged echolucent structure was seen along the course of the right common peroneal and sciatic nerve. This mass lesion was traced for $15 \mathrm{~cm}$ from the lateral aspect of the popliteal fossa and involved the sciatic nerve up to the buttock.

Magnetic resonance imaging revealed a lobulated welldemarcated cystic lesion at the posterior lateral knee region along the course of the common peroneal and sciatic nerves. This lesion had a cystic component at the bifurcation point of the sciatic nerve into the common peroneal nerve and the tibial nerve (Figure 1A, B).

We identified the cystic formation at the bifurcation of sciatic nerve per-operatively, as anticipated pre-operatively. Common peroneal and sciatic nerves were diffusely enlarged in the vicinity of this huge cyst. An intraneural cyst along the common peroneal and sciatic nerve was identified and decompressed, but not was not resected (Figure 2). The tumor had no connection with the proximal tibiofibular joint or with the knee joint. Histopathological evaluation of the decompressed gelatinous material verified the diagnosis of ganglion (Figure 3). The patient recovered to Grade 3 toe extension and ankle dorsiflexion within a couple weeks after the surgery. There were no clinical signs of recurrence during a short follow-up period.

\section{DISCUSSION}

Ganglion cysts are benign mucinous lesions that typically occur near the joints so that they may affect adjacent nerves by a mass effect. These cysts may be classified as intraneural or extraneural. Although they are rare, intraneural ganglions located within the substance of nerves, they may cause direct nerve compression as in our case. The ganglion cyst was located intraneurally and caused compression of the
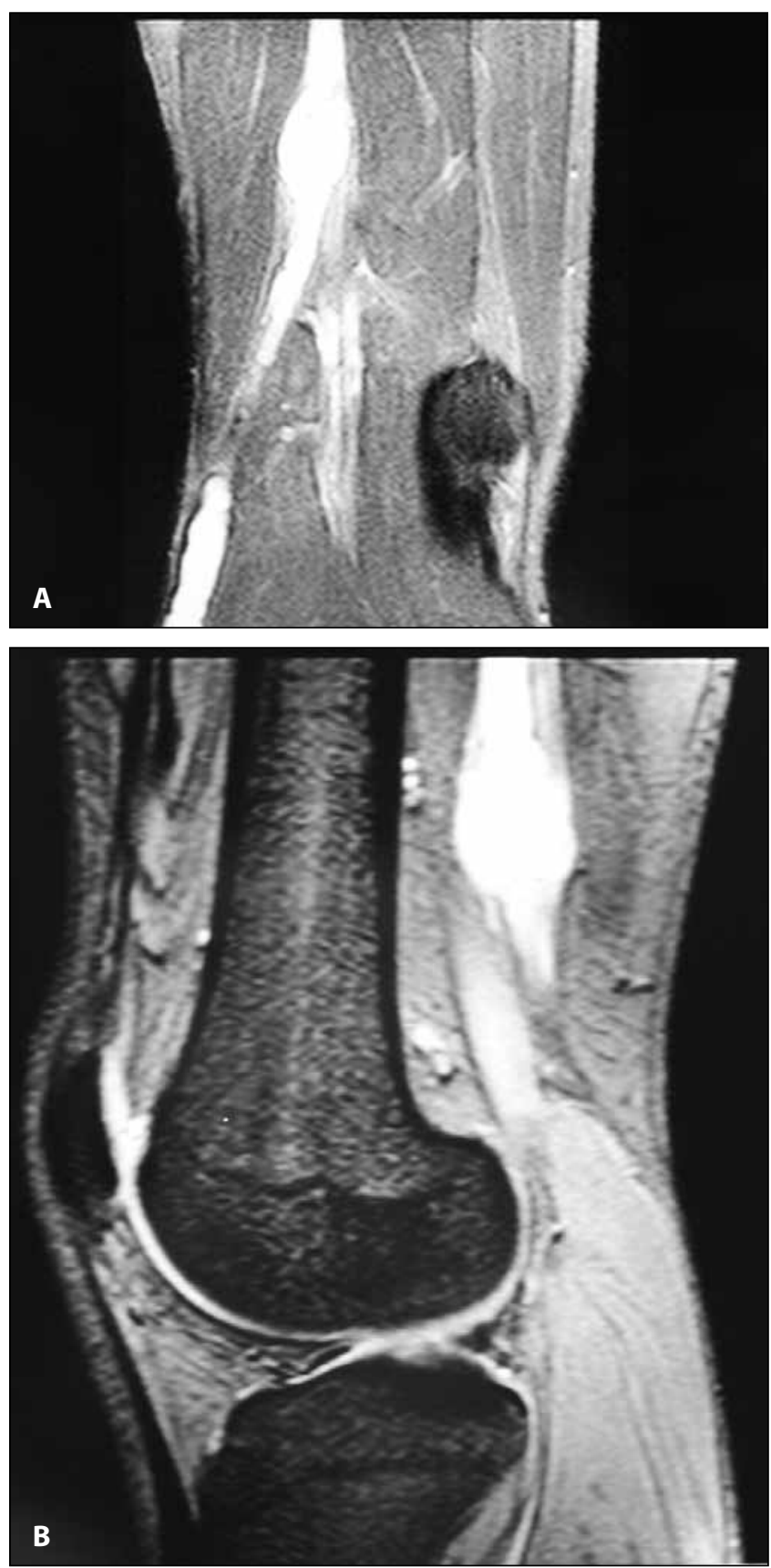

Figure 1: A) T2-weighted coronal MR image of the right leg shows a lobulated, enlarged cystic lesion along the course of the common peroneal and sciatic nerve. B) T2-weighted sagittal MR image of the right leg shows a cystic mass at the sciatic nerve bifurcation.

common peroneal nerve in our patient. Foot weakness was therefore the presenting symptom.

Intraneural ganglion cysts are usually located within the epineurium of the nerve. The mechanism underlying their formation has been controversial since the first published description of such a case in the English literature was over one-hundred years ago (11). 


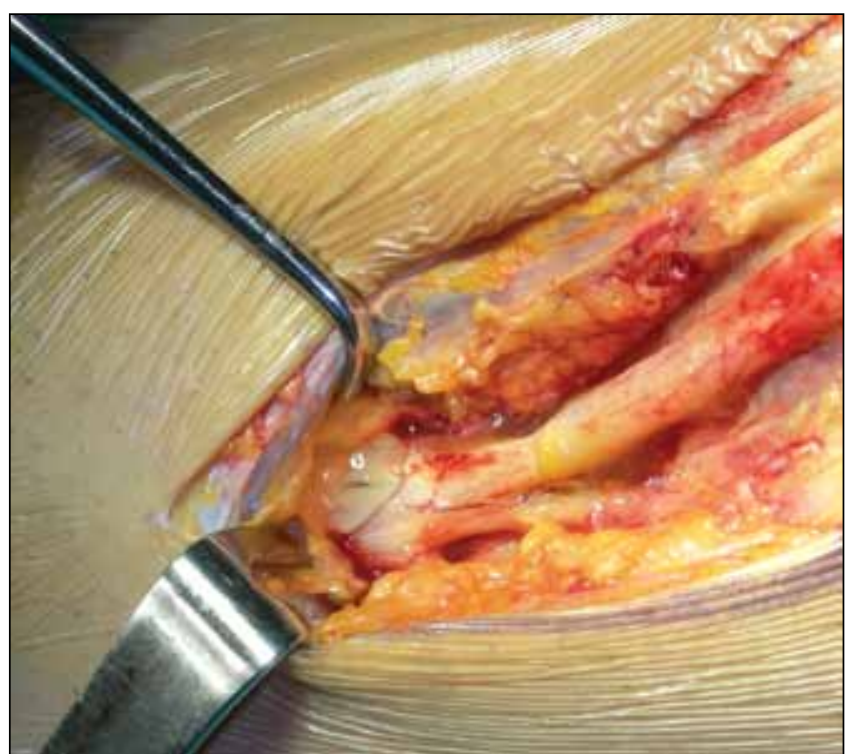

Figure 2: Intraoperative photograph showing enlarged, thickened common peroneal nerve and sciatic nerve bifurcation. The tibial nerve segment seems unaffected. A definite cyst can be easily identified on dissection of the sciatic nerve bifurcation.

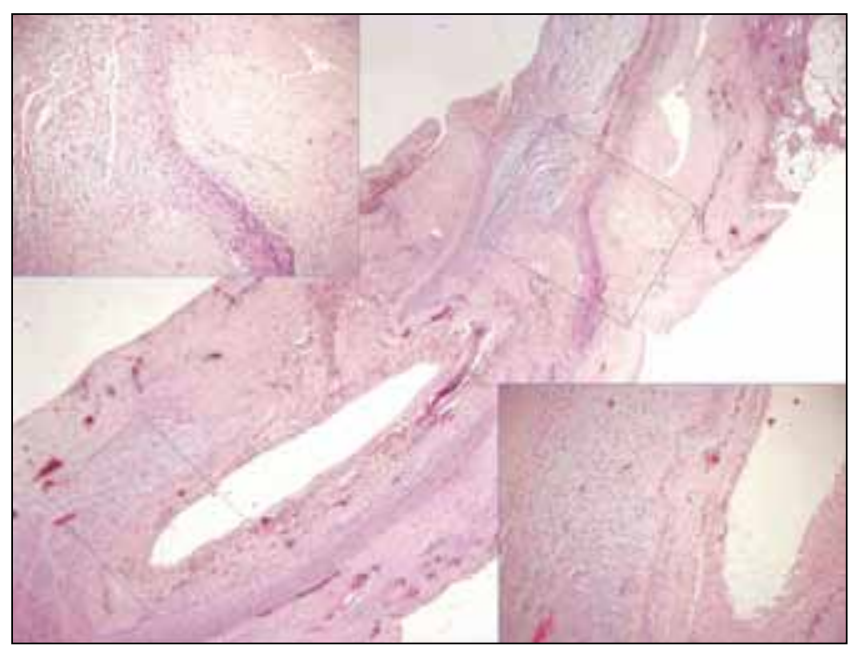

Figure 3: Ganglion of nerve sheath with myxoid change and cystic degeneration seen in the connective tissue of the nerve (H\&E x 20, x100).

Hartwell described involvement of the median nerve by a ganglion in 1901 (11). Brooks described 13 cases of peripheral nerve compression due to ganglia in 1952 (2).Three of these 13 reported cases involved the peroneal nerve. Stack et al. (28) described 9 cases of compression of the peroneal nerve in 1965. Synovial cysts compressing the peroneal nerve may be extraneural or intraneural (7). Nevertheless, Brooks (2) suggested that these are anatomical variants of the same entity.

The common peroneal nerve is one of the main branches of the sciatic nerve and it arises near the upper level of the popliteal fossa. The nerve has a course along the lateral aspect of the popliteal fossa and around the fibular head, it divides into the superficial peroneal and deep peroneal nerves. It is responsible for the motor supply to all the dorsiflexor and everter muscles of the foot and for the sensory innervation to the anterolateral aspect of the leg proximally and to the dorsum of the foot. Hence, a lesion of the common peroneal nerve would result in foot drop. Additionally, it gives off at least four articular branches during its course, one of which is the recurrent articular nerve that supplies the superior tibiofibular joint (3).

These cysts are commonly accompanied by signs of nerve irritation such as numbness, tingling, and pain in the distribution of the affected nerve. A mass may also be palpated along the lateral aspect of the knee in proximity to the fibular head. Tinel's sign may also be present. Except for the palpable mass, our patient had all of the symptoms suggestive of peroneal nerve involvement and we think that this symptomatology in the absence of a palpable mass lesion was the major factor that misled the neurosurgeon and resulted in the misdiagnosis of lumbar discopathy.

Regardless of the origin of the intraneural ganglion, a thorough understanding of the pathomechanism of the common peroneal nerve palsy is very important in treating the lesions accordingly. There has been controversy regarding the origin of the so-called "intraneural" ganglion $(1,22)$. While some authors reported an apparent connection between the ganglion and the proximal tibiofibular joint, others, including ourselves, found no such connection in our patient. Poppi et al. reported a purely intraneural ganglion(23). Our surgical observations and radiological features did not show any connection between the ganglion and the proximal tibiofibular joint. Thus, this case can be considered a purely intraneural ganglion as reported by Poppi et al.

We found very few reported cases of an intraneural ganglion that involved the sciatic nerve $(10,14,16,17,29)$. There are three potential mechanisms regarding the formation of ascending peroneal intraneural ganglion cysts to the level of the sciatic nerve without cross-over or terminal branch descent $(10,16,29)$ : (1) dissection within the inner epineurium, (2) the presence of a high sciatic nerve bifurcation, as is known to occur in approximately $10 \%$ of cadavers, with two distinct but contiguous outer epineuria separating the common fibular and tibial nerves, and (3) unrecognized cyst involvement in the other nerves. We believe that sciatic nerve involvement in this case occurred as a result of dissection within the inner epineurium although we could not find convincing evidence.

Ultrasonography or MRI can be used as the imaging technique to confirm the diagnosis (20). Both imaging techniques were performed simultaneously in the present case. USG is an effective, cheap and noninvasive diagnostic method to identify the cyst. Ultrasound demonstrates the cyst as a wellcircumscribed and anechoic lesion $(5,17,18,19)$. However, it does not provide a clear definition of the surrounding tissues (5). MRI may be used to identify the anatomical relation of 
the cysts to the joint and surrounding structures, as well as to evaluate the presence of associated knee abnormalities. A detailed examination seems to be an obvious advantage of MRI, but it is more expensive than USG. The MRI appearance of peroneal intraneural ganglia is stereotypic and can be reliably distinguished from extraneural ganglia. Peroneal intraneural ganglia are tubular and follow the course of the articular branch (26). Although we performed MRI, the articular branch was not affected by the peroneal intraneural ganglion.

Other imaging modalities such as CT and arthrography can be used for the diagnosis of an intraneural ganglion cyst. CT shows the ganglion as a round, sometimes bi- or multiloculated mass with a thin and well defined wall that does not enhance after contrast agent administration. The relationship between the cyst and the nerve may be best evaluated with high resolution CT $(6,21)$.

The preoperative diagnosis of peroneal intraneural ganglion has been difficult to establish and superior tibiofibular joint connections may not be identified. Misdiagnosis leads to incomplete treatment in that the articular branch connection may not be addressed which can result in cyst recurrences (26).The radiographic features of ganglia are distinct. Ganglia should be easily differentiated from other cystic and solid mass (such as schwannomas, myxomas or synovial sarcomas) by the lack of contrast enhancement and the identification of a joint connection (20).

The differential diagnosis should include L5 root pathology, posttraumatic intraneural hemorrhage, nerve compression near the tendinous arch located at the fibular insertion of the peroneal longus muscle and a nerve sheath tumor $(8,9,13,24)$. Positive Tinnel sign and tenderness at the lateral aspect of poplitea near the fibular neck were the keys to differentiating the L5 root pathology in our patient. Further investigations can be done to avoid a misdiagnosis.

The most reliable technique of treatment involves complete surgical excision of the cyst, given that the recurrence rate for aspiration of an intraneural ganglion alone has been reported at about $30 \%$ (4). Moreover, It is recommended that the treatment must be as simple and conservative as possible, requiring either decompression or - if feasible - total removal of the cyst. This should be accompanied by ligation of the stalk/ pedicle, and most importantly the articular branch of the peroneal nerve should be sectioned to prevent recurrence (25).

Simple and conservative surgery was planned in our case of pure peroneal intraneural ganglia ascending along the sciatic nerve. A longitudinal epineurial incision was made away from the fascicles, centered over a cystic bleb. Gelatinous material was evacuated under some pressure. The limited epineurotomy decompressed the cyst effectively without causing any obvious neural injury.

In conclusion; this case underlines the importance of consideration of an uncommon, pure peroneal intraneural ganglion ascending along the sciatic nerve. Intraneural ganglion cysts should be considered in the differential diagnosis of progressive peroneal or sciatic nerve palsy. Other clinical entities that should be considered in the differential diagnosis include L5 root lesions and nerve sheath tumours arising from the lateral compartment of the knee. The treatment of peroneal intraneural ganglion cysts must be surgical intervention as soon as possible and include decompression of the nerve with excision of the tibiofibular joint connection to prevent peroneal nerve palsy and recurrence.

\section{REFERENCES}

1. Barrett R, Cramer F: Tumors of the peripheral nerves and socalled "ganglia" of the peroneal nerve. Clin Orthop 27:135-146, 1963

2. Brooks DM: Nerve compression by simple ganglia: $A$ review of thirteen collected cases. J Bone Joint Surg (Br) 34:391-400, 1952

3. Davies DV: Gray's Anatomy: 34th edition, 3rd impression. Coupland RE: Longmans, Longuang 1972:1224-1236

4. Donahue F, Turkel DH, Mnaymneh W: Intraosseous ganglion cyst associated with neuropathy. Skeletal Radiol 25:675-678, 1996

5. Dubuisson AS, Stevenaert A: Recurrent ganglion cyst of the peroneal nerve: Radiological and operative observations. J Neurosurg 84:280-283,1996

6. Gambari PI, Guiliani G, Poppi M, Pozzati E: Ganglion cysts of the peroneal nerve at the knee: CT and surgical correlation. J Comput Assist Tomogr 14:801-803, 1990

7. Ghossain M, Mohasseb G, Dagher F, Ghossain A: Compression of the common peroneal nerve by a synovial cyst. Neurochirurgie 33:412-413, 1987

8. Godin V, Huaux JP, Knoops P, Noel H, Rombouts JJ: Une cause rare de paralysie des muscles releveurs du pied; le kyste synovial intraneural du SPE. Louvain Med 104:281-286, 1985

9. Gurdjian ES, Larsen RD, Lindner DW: Intraneural cyst of the peroneal and ulnar nerves. Report of two cases. J Neurosurg 23:76-78, 1965

10. Harbaugh KS, Tiel RL, Kline DG: Ganglion cyst involvement of peripheral nerves. J Neurosurg 87:403-408, 1997

11. Hartwell AS: Cystic tumor of median nerve, operation: Restoration of function. Boston Med Surg J 144:582-583,1901

12. Hislop HJ, Montgomery J: Daniels and Worthingham's muscle testing:Techniques of manual examination, 6th ed. Philadelphia: WB Saunders, 1995

13. Huaux JP, Malghem J, Maldague B, Noel H, Rombouts JJ, Courtois C, Nagant de Deuxchaisnes C: Pathology of the upper peroneotibial joint. History of cysts. Apropos of 4 cases. Rev Rhum Mal Osteoartic 53:723-726, 1986

14. Jacobs RR, Maxwell JA, Kepes J: Ganglia of the nerve. Presentation of two unusual cases, a review of the literature, and a discussion of pathogenesis. Clin Orthop Relat Res 113:135-144, 1975

15. Katz MR, Lenobel MI: Intraneural ganglionic cyst of the peroneal nerve. J Neurosurg 32:692-694, 1970

16. Krishnan KG, Schackert G: Intraneural ganglion cysts: A case of sciatic nerve involvement. Br J Plast Surg 56:183-186, 2003

17. Lang CJ, Neubauer U, Qaiyumi S, Fahlbusch R: Intraneural ganglion of the sciatic nerve: Detection by ultrasound. J Neurol Neurosurg Psychiatry 57:870-871, 1994 
18. Leijten FSS, Arts WF, Puylaret JBCM: Ultrasound diagnosis of an intraneural ganglion cyst of the peroneal nerve. J Neurosurg 76:538-540, 1992

19. Masciocchi C, Innacoli M, Cisternino S, Barile A, Rossi F, Passariello R: Myxoid intraneural cysts of the external popliteal ischiadic nerve. Report of 2 cases studied with ultrasound, computed tomography and magnetic resonance imaging. Eur J Radiol 14:52-55, 1992

20. McCarthy $C L$, McNally EG: The MRI appearance of cystic lesions around the knee. Skelet Radiol 33:187-209, 2004

21. Nucci F, Artico M, Santoro A: Intraneural synovial cyst of the peroneal nerve: Report of two cases and review of the literature. Neurosurgery 26:339-344, 1990

22. Parks A: Intraneural ganglion of the lateral popliteal nerve. J Bone Joint Surg Br 43:784-790, 1961

23. Poppi M, Nasi MT, Giuliani G, Acciarri N, Montagna P: Intraneural ganglion of the peroneal nerve: An unusual presentation. Surg Neurol 31:405-406, 1989
24. Sidey JD: Weak ankles. A study of common peroneal entrapment neuropathy. Br Med J 3:623-626, 1969

25. Spinner RJ, Atkinson JL, Scheithauer BW, Rock MG, Birch R, Kim TA: Peroneal intraneural ganglia: The importance of the articular branch: Clinical series. Journal of Neurosurgery 99:319-329, 2003

26. Spinner RJ, Desy NM, Amrami KK: Cystic transverse limb of the articular branch: A pathognomonic sign for peroneal intraneural ganglia at the superior tibiofibular joint. Neurosurgery 59: 157-166, 2006

27. Spinner RJ: Lettre à la rédaction. Rev Chir Orthop 91:492-494, 2005

28. Stack RE, Bianco AJ, MacCarthy CS: Compression of the common peroneal nerve by ganglion cysts. J Bone Joint Surg (Am) 47: 773-778, 1965

29. Wadstein T: Two cases of ganglia in the sheath of the peroneal nerve. Acta Orthop Scand 2:221-230, 1931 